\title{
Uranium Monosulfide. The Ferromagnetic Transition. The Heat Capacity and Thermodynamic Properties from $1.5^{\circ}$ to $350^{\circ} \mathrm{K}^{*}$
}

\author{
Edgar F. Westrum, JR. \\ Department of Chemistry, University of Michigan, Ann Arbor, Michigan \\ AND
}

Robert R. Walters, Howard E. Flotow, and Darrell W. Osborne

Argonne National Laboratory, Argonne, Illinois

(Received 15 September 1967)

\begin{abstract}
The heat capacity of uranium monosulfide was measured from $1.5^{\circ}$ to $22^{\circ} \mathrm{K}$ by an isothermal (isoperibol) method and from $6^{\circ}$ to $350^{\circ} \mathrm{K}$ by an adiabatic technique. The ferromagnetic transition at $180.1^{\circ} \mathrm{K}$ has a characteristic lambda shape and associated magnetic ordering entropy and enthalpy increments of $1.6_{2} \pm 0.2$ $\mathrm{cal}^{\circ} \mathrm{K}^{-1} \mathrm{~mole}^{-1}$ and $231 \pm 20 \mathrm{cal} \mathrm{mole}^{-1}$, respectively, over the temperature range $0^{\circ}$ to $230^{\circ} \mathrm{K}$. The correlation of the thermal data with magnetic studies is discussed. The heat capacity below $9^{\circ} \mathrm{K}$ is represented by $C_{p}=5.588 \times 10^{-3} \mathrm{~T}+2.627 \times 10^{-4} \mathrm{~T}^{3 / 2}+6.752 \times 10^{-5} \mathrm{~T}^{3} \mathrm{cal}{ }^{\circ} \mathrm{K}^{-1} \mathrm{~mole}^{-1}$, in which the successive terms represent conduction electronic, magnetic, and lattice contributions. Values of the entropy $\left[S^{\circ}\right]$, enthalpy function $\left[\left(H^{\circ}-H^{\circ}{ }_{0}\right) / T\right]$, and Gibbs-energy function $\left[\left(G^{\circ}-H^{\circ}{ }_{0}\right) / T\right]$ are $18.64 \pm 0.05,8.94 \pm 0.02$, and $-9.70 \pm 0.02$ cal ${ }^{\circ} \mathrm{K}^{-1} \mathrm{~mole}^{-1}$, respectively, at $298.15^{\circ} \mathrm{K}$. The Gibbs energy of formation at $298.15^{\circ} \mathrm{K}$ is $-72.9 \pm 3.5 \mathrm{kcal}$ mole $^{-1}$.
\end{abstract}

\section{INTRODUCTION}

Recent interest in the crystal structures, vaporization, and magnetic behavior of the lanthanide and actinide monochalcogenides and the potential utilization of the latter as a reactor fuel has already produced a significant literature. The present paper is an endeavor to explore some thermal properties of uranium monosulfide and thereby establish its thermodynamic behavior. Thermodynamics of the formation process are evaluated and found to be at variance with estimates in the literature. In the course of the heat-capacity measurements a lambda-type anomaly was found near $180.1^{\circ} \mathrm{K},{ }^{1}$ which was later shown to be associated with a ferromagnetic transition. ${ }^{2}$ Tables of the heat capacity and other thermodynamic functions are presented, and the thermodynamic functions are resolved into the electronic, lattice, and magnetic contributions.

\section{EXPERIMENTAL}

\section{A. Preparation and Characterization of the Sample}

Two sets of heat-capacity measurements were made. The first, made at the University of Michigan, covered the temperature range $6^{\circ}$ to $350^{\circ} \mathrm{K}$. The second set was made four years later at the Argonne National Laboratory over the range $1.5^{\circ}$ to $22^{\circ} \mathrm{K}$. Because the composition of the sample changed slightly by exposure to

\footnotetext{
* Based on work performed under the auspices of the U.S. Atomic Energy Commission.

${ }^{1}$ A preliminary report was given by E. F. Westrum, Jr. and F. Gronvold in Thermodynamics of Nuclear Materials (International Atomic Energy Agency, Vienna, 1962), pp. 3-37.

${ }^{2}$ M. A. Kanter and C. Kazmierowicz, Bull. Am. Phys. Soc. 7, $556(1962)$.
}

the atmosphere and consequent reaction with oxygen or moisture, individual characterization of the sample is required for each set of data.

The sample was prepared from high-purity uranium metal of natural isotopic composition in 4- and 13-g batches by Method 4 of Eastman et al. ${ }^{3}$ as adapted by Cater, Gilles, and Thorn. ${ }^{4}$ Hence, the metal was first hydrogenated, subsequently decomposed, and then reacted with hydrogen sulfide to form a loosely sintered mass of a higher sulfide and $\alpha$-uranium of proper overall stoichiometry. This reaction product was ground and thoroughly mixed in a boron carbide mortar within an argon-atmosphere drybox; it was transferred to a degassed, spun tantalum crucible and homogenized by heating in high vacuum $\left(<10^{-6}\right.$ torr) at $2100^{\circ} \mathrm{C}$ for $7.5 \mathrm{~h}$. After sampling for analytical purposes, the resultant material was ground again and pelleted in a hardened steel die, annealed in a tantalum crucible at $1900^{\circ} \mathrm{C}$ for $1.5 \mathrm{~h}\left(<10^{-6}\right.$ torr $)$, and allowed to cool to room temperature over a 12 -h period. The three cylinders were brightly metallic, with the luster and appearance of silver.

Spectrochemical analyses of the sample resulted in the detection of the following impurities (in ppm) : Fe (70), $\mathrm{Si}(60), \mathrm{Cu}(20), \mathrm{Al}(10), \mathrm{Mg}(10), \mathrm{Ni}(10)$, $\mathrm{Mn}(5), \mathrm{Pb}(5)$, and $\mathrm{Cr}$ (2). The following elements were not detected, and the limits of detection were as indicated (in ppm): $\mathrm{K}, \mathrm{P}, \mathrm{Ti}$, and $\mathrm{Zn}(<50)$; $\mathrm{Ca}$ and Mo $(<20)$; As and $\mathrm{Na}(<10)$; $\mathrm{Co}$ and $\mathrm{Sm}(<10)$; $\mathrm{Ag}, \mathrm{B}, \mathrm{Be}, \mathrm{Bi}, \mathrm{Li}$, and $\mathrm{Sb}(<1)$. A special spectrochemical analysis for tantalum after the high-tem-

${ }^{3}$ E. D. Eastman, L. Brewer, L. A. Bromley, P. W. Gilles, and N. L. Lofgren, J. Am. Chem. Soc. 72, 4019 (1950).

4 E. D. Cater, P. W. Gilles, and R. J. Thorn, J. Chem. Phys. 35, 155 
TABre I. Heat capacity of uranium monosulfide, in cal ${ }^{\circ} \mathrm{K}^{-1}$ mole $^{-3}$, measured at the University of Michigan. A correction for curvature has been applied to atl points except those for which the temperature increment $\Delta T$ is given in a footnote. Mole wt $=$ $270.09 ; 0^{\circ} \mathrm{C}=273.15^{\circ} \mathrm{K}$.

\begin{tabular}{rrrrrr}
\hline$T\left({ }^{\circ} \mathrm{K}\right)$ & \multicolumn{1}{c}{$C_{p}$} & $\bar{T}\left({ }^{\circ} \mathrm{K}\right)$ & \multicolumn{1}{c}{$C_{p}$} & $\bar{T}\left({ }^{\circ} \mathrm{K}\right)$ & $C_{\mathrm{p}}$ \\
\hline Series I & & 126.29 & 9.602 & 183.92 & 11.89 \\
& & 134.72 & 10.336 & 185.13 & 11.71 \\
7.05 & 0.063 & 143.32 & 11.109 & 186.73 & 11.57 \\
8.18 & 0.087 & 151.83 & 11.987 & 191.12 & 11.39 \\
9.46 & 0.116 & 160.71 & 13.074 & & \\
10.78 & 0.154 & 169.77 & 14.707 & Series III \\
12.13 & 0.205 & 178.69 & $16.870^{\mathrm{a}}$ & & \\
13.52 & 0.272 & 188.34 & $11.530^{\mathrm{b}}$ & 168.33 & 14.39 \\
15.00 & 0.364 & 198.74 & 11.27 & 170.54 & 14.91 \\
16.59 & 0.477 & 208.39 & 11.31 & 172.71 & 15.60 \\
18.26 & 0.619 & 217.30 & 11.38 & 175.74 & 16.89 \\
20.09 & 0.809 & 226.36 & 11.47 & 178.53 & 18.88 \\
22.15 & 1.043 & 235.73 & 11.63 & 179.85 & $20.54^{\circ}$ \\
24.45 & 1.310 & 245.08 & 11.72 & 180.86 & 16.51 \\
27.03 & 1.632 & 254.34 & 11.74 & 181.96 & 12.74 \\
29.81 & 1.990 & 263.52 & 11.80 & 185.27 & 11.71 \\
32.80 & 2.335 & 272.64 & 11.90 & & \\
36.13 & 2.718 & 281.73 & 11.98 & & Series $\mathrm{IV}$ \\
39.76 & 3.085 & & & & \\
43.84 & 3.474 & Series $\mathrm{II}$ & 172.81 & $14.10^{\mathrm{d}}$ \\
48.61 & 3.904 & & & & \\
54.01 & 4.345 & 173.01 & 15.46 & & Series $\mathrm{V}$ \\
59.57 & 4.756 & 174.13 & 16.05 & & \\
65.40 & 5.180 & 175.22 & 16.51 & 277.95 & 11.88 \\
72.13 & 5.635 & 176.30 & 17.10 & 287.14 & 11.97 \\
79.38 & 6.137 & 177.37 & 17.89 & 296.36 & 12.10 \\
86.56 & 6.718 & 178.42 & 18.64 & 305.70 & 12.15 \\
94.00 & 7.225 & 179.44 & $20.01 \mathrm{e}$ & 315.06 & 12.19 \\
101.72 & 7.742 & 180.46 & $19.02^{\mathrm{f}}$ & 323.49 & 12.25 \\
109.82 & 8.316 & 181.55 & 13.47 & 330.95 & 12.32 \\
118.31 & 8.969 & 182.73 & 12.18 & 338.48 & 12.34 \\
& & & & 346.15 & 12.38
\end{tabular}

$\begin{array}{ll}\text { a } \Delta T=8.877^{\circ} \mathrm{K} . & \text { d } \Delta T=36.069^{\circ} \mathrm{K} . \\ \text { b } \Delta T=10.401^{\circ} \mathrm{K} . & \text { o } \Delta T=1.001^{\circ} \mathrm{K} . \\ \text { o } \Delta T=0.961^{\circ} \mathrm{K} . & \text { f } \Delta T=1.020^{\circ} \mathrm{K} .\end{array}$

perature annealing but prior to pelleting showed 14-ppm tantalum.

Analyses for sulfur were performed prior to making the final pellets by dissolving 30 to $100 \mathrm{mg}$ of the sample in $3.6 \mathrm{~N}$ sulfuric acid, absorbing the hydrogen sulfide produced in an ammoniacal solution containing a weighed quantity of silver nitrate, and titrating the excess silver with standard potassium thiocyanate in the presence of ferric iron as indicator. ${ }^{5}$ Duplicate analyses indicated $11.86 \pm 0.10 \mathrm{wt} \%$ sulfur (theoretical, $11.87 \%$ ). As has already been pointed out by Cater $e t$ $a l .,{ }^{4}$ slight oxygen contamination (e.g., $0.01 \%$ ) results in the formation of uranium dioxide and uranium oxysulfide phases which remain undissolved in the course of

${ }^{5}$ I. M. Kolthoff and J. J. Lingane, J. Am. Chem. Soc. 57, 2126 (1935). the sulfide analytical procedure and hence can be weighed and identified by $x$-ray diffraction. No insoluble residue was present in this material. $\mathrm{X}$-ray powder diffraction photographs of the homogenized sample revealed only the lines characteristic of uranium monosulfide and yielded a lattice parameter $a_{0}$ of $5.4879 \pm 0.0002 \AA$. Although no direct analysis was made for uranium, the data indicate that the $S / U$ ratio was $1.00 \pm 0.01$ initially. (The above values characterize the sample used for the heat capacity measurements from $6^{\circ}$ to $350^{\circ} \mathrm{K}$ presented in Table I.)

By the time the second set of measurements was started, the sample color had changed to a uniform bronze throughout. After the conclusion of the measurements it was again analyzed. The lattice constant $a_{0}$ was found to be $5.488 \pm 0.001 \AA$, in agreement with the previous value. The oxygen content was determined by inert-gas fusion ${ }^{6}$ to be $0.16 \pm 0.01 \mathrm{wt} \%$. Total uranium was determined as $87.95 \pm 0.16 \mathrm{wt} \%$ from the weight gain on ignition to $\mathrm{U}_{3} \mathrm{O}_{8}$. A residue insoluble in $3.6 \mathrm{~N}$ sulfuric acid amounted to $1.55 \pm 0.05 \mathrm{wt} \%$ of the sample. X-ray diffraction of the residue showed only two phases, uranium dioxide and uranium oxysulfide, with the former predominant. From these results the composition of the sample (for the data reported in Table II) (in mole fraction) is $0.9847 \mathrm{US}, 1.17 \mathrm{UO}_{2}$, and 0.36 UOS. The theoretical values for this composition (in wt \%) are $88.11 \mathrm{U}, 11.73 \mathrm{~S}$, and $0.16 \mathrm{O}$. The total sulfur determined by a method involving complete dissolution of the sample in perchloric acid and

TABLE II. Heat capacity of uranium monosulfide, in cal ${ }^{\circ} \mathrm{K}^{-1}$ mole ${ }^{-1}$, measured at Argonne National Laboratory. The apparent $C_{p}$ values were calculated with the assumption of a pure US sample, and the corrected $C_{p}$ values were adjusted for the presence of 1.17 mole $\% \mathrm{UO}_{2}$ and 0.36 mole $\%$ UOS.

\begin{tabular}{|c|c|c|c|c|c|}
\hline $\bar{T}$ & $\underset{C_{p}}{\text { Apparent }}$ & $\begin{array}{c}\text { Corrected } \\
C_{p}\end{array}$ & $\bar{T}$ & $\underset{C_{p}}{\text { Apparent }}$ & $\begin{array}{c}\text { Corrected } \\
C_{p}\end{array}$ \\
\hline 1.568 & 0.00934 & 0.00948 & 6.326 & 0.05611 & 0.05680 \\
\hline 1.709 & 0.01029 & 0.01044 & 6.931 & 0.06521 & 0.06596 \\
\hline 1.879 & 0.01142 & 0.01159 & 7.55 .5 & 0.07575 & 0.07656 \\
\hline 2.052 & 0.01262 & 0.01281 & 8.239 & 0.08887 & 0.08973 \\
\hline 2.249 & 0.01402 & 0.01423 & 9.004 & 0.1056 & 0.1065 \\
\hline 2.473 & 0.01564 & 0.01587 & 9.843 & 0.1273 & 0.1282 \\
\hline 2.709 & 0.01743 & 0.01769 & 10.764 & 0.1552 & 0.1560 \\
\hline 3.043 & 0.02001 & 0.02030 & 11.809 & 0.1931 & 0.1939 \\
\hline 3.340 & 0.02246 & 0.02279 & 13.056 & 0.2496 & 0.2502 \\
\hline 3.685 & 0.02549 & 0.02586 & 14.386 & 0.3238 & 0.3241 \\
\hline 4.054 & 0.02889 & 0.02931 & 15.688 & 0.4115 & 0.4116 \\
\hline 4.474 & 0.03311 & 0.03358 & 15.777 & 0.4175 & 0.4176 \\
\hline 4.659 & 0.03512 & 0.03561 & 17.239 & 0.5337 & 0.5334 \\
\hline 5.130 & 0.04044 & 0.04099 & 18.963 & 0.6917 & 0.6905 \\
\hline 5.693 & 0.04735 & 0.04796 & 20.802 & 0.8830 & 0.8806 \\
\hline
\end{tabular}

${ }^{6}$ W. G. Smiley, Anal. Chem. 27, 1098 (1955). 
conversion of the sulfur to barium sulfate was $11.90 \pm 0.12 \mathrm{wt} \%$, and the sulfur content of the soluble portion by the method described above ${ }^{5}$ was $12.02 \pm 0.12$ wt $\%$. These values indicate that the $S / U$ ratio in the soluble portion was $1.015 \pm 0.012$. This agrees with the original ratio of $1.00 \pm 0.01$ within the experimental errors.

\section{B. Calorimetric Technique, University of Michigan, $6^{\circ}$ to $350^{\circ} \mathrm{K}$}

Measurements were made by the intermittent heating technique ${ }^{7}$ in the Mark II adiabatic calorimetric cryostat previously described ${ }^{8}$. This was provided with an electronic, adiabatic shield control consisting of three separate channels of recording circuitry with proportional, rate, and reset control actions which maintained temperature equality with the calorimeter within a millidegree and thereby reduced heat exchange with the surroundings to an amount negligible in comparison with other sources of error. A special gold-plated calorimeter (laboratory designation W-34) of mass $10.5 \mathrm{~g}$ (plus approximately $7 \mathrm{~g}$ of platinum-resistance thermometer, heater sleeve, and spool), machined from OFHC copper rod, was used. The sample space of $8.0 \mathrm{cc}$ was sealed with Cerroseal (indium-tin) solder. Temperatures were determined with a capsule-type, platinum-resistance thermometer (laboratory designation A-3) in a thermometer-heater well which was mounted somewhat off the axis of the sample space. The temperatures are considered to accord with the thermodynamic temperature scale within $0.03^{\circ} \mathrm{K}$ from $10^{\circ}$ to $90^{\circ} \mathrm{K}$ and within $0.04^{\circ} \mathrm{K}$ from $90^{\circ}$ to $350^{\circ} \mathrm{K}$.

The heat capacity of the empty calorimeter was determined separately with appropriate small adjustments for the slight differences in the amounts of several adjuvant substances on the loaded and empty calorimeter. In particular these involved amounts of helium gas (about 100-torr pressure, used to enhance thermal contact between calorimeter and sample), of Cerroseal solder, and of Apiezon $\mathrm{T}$ grease (for thermal contact between calorimeter, thermometer, heater, and thermocouples). The mass of the three cylindrical specimens comprising the sample was $15.326 \mathrm{~g}$ (in vacuo). A density of $10.87 \mathrm{~g} / \mathrm{cc}$ was used for buoyancy corrections. Despite the small mass of the calorimeter, the heat capacity of the sample represented only about $27 \%$ of the total above the transition and increased to $37 \%$ at $175^{\circ}$ and to $50 \%$ below $10^{\circ} \mathrm{K}$. All determina-

${ }^{7}$ E. F. Westrum, Jr., G. T. Furukawa, and J. P. McCullough, "Adiabatic Low-Temperature Calorimetry," in Experimental Thermodynamics, J. P. McCullough and D. W. Scott, Eds. (Butterworths Scientific Publications, Ltd,, London, 1967).

8 E. F. Westrum, Jr., and J. P. McCullough,"Thermodynamics of Crystals," in Physics and Chemistry of the Organic Solid State, D. Fox, M. M. Labes, and A. Weissberger, Eds. (Interscience Publishers, Inc., New York, 1963), Vol. 1, pp. 1-178. [See Fig. 2 and accompanying description.] tions of mass, current, voltage, time, and temperature were referred to calibrations or standardizations performed by the National Bureau of Standards.

\section{Calorimetric Technique, Argonne National Laboratory, $1.5^{\circ}$ to $22^{\circ} \mathrm{K}$}

The calorimetric apparatus and measuring technique have been described in detail in a previous publication," which also reports the calibration of the germanium resistance thermometer (laboratory designation $\mathrm{Ge} \mathrm{No}$. 3) used for these measurements and the results obtained in the same apparatus for a sample from the 1965 Calorimetry Conference Copper Standard. The technique is an isothermal one in which a copper ring ${ }^{10}$ to which the leads and supports are thermally anchored is held constant to $\pm 0.001^{\circ} \mathrm{K}$ with an automatic control circuit.

The three cylindrical specimens used at the University of Michigan were crushed to a powder in a helium-filled dry box and then encapsulated within a thin-walled $(0.06 \mathrm{~mm})$ right annular copper cylinder and pressed within a hardened steel die. By this means adequate thermal conductivity was obtained between the copper capsule and the entire sample, and no helium exchange gas was required in the calorimeter." The copper-encapsulated specimen fit over a re-entrant well in the calorimeter. ${ }^{12}$ Thermal contact between the capsule and the calorimeter was effected by about $9 \mathrm{mg}$ of Apiezon $\mathrm{T}$ grease which bridged the $0.003-\mathrm{cm}$ inner radial clearance between the parts. After sealing the lid on the calorimeter with a weighed amount of Cerroseal solder, the calorimeter was transferred from the helium-filled dry box to a vacuum line, where the helium was evacuated through a $0.5-\mathrm{mm}$ hole provided for this purpose, and the hole was soldered shut. The mass of the sample in the capsule was $14.344 \mathrm{~g}$ in vacuo.

The heat capacity of the empty calorimeter was determined in a separate series of measurements. Small adjustments for differences in the amounts of solder, copper, and Apiezon $\mathrm{T}$ grease between the full and empty calorimeter were applied. These were based upon the measured heat capacities of copper ${ }^{9}$ and Apiezon T grease $^{13}$ and an estimated heat capacity for the solder. The total uncertainty resulting from these calculated corrections is judged to be less than $0.1 \%$ of the reported values. The sample accounted for about $75 \%$ of the total measured heat capacity at $1.5^{\circ} \mathrm{K}$, about $60 \%$ at $5^{\circ} \mathrm{K}$, and about $50 \%$ above $10^{\circ} \mathrm{K}$.

\footnotetext{
- D. W. Osborne, H. E. Flotow, and F. Schreiner, Rev. Sci. Instr. 38, 159 (1967)

${ }^{10}$ Compare Fig. 1, Ref. 9.

$11 \mathrm{H}$. E. Flotow and D. W. Osborne, Rev. Sci. Instr. 37, 1414 (1966).

${ }_{12}$ Compare Fig. 4, Ref. 9.

${ }^{13}$ E. F. Westrum, Jr., C. Chou, D. W. Osborne, and H. E. Flotow, Cryogenics 7, 43 (1967).
} 


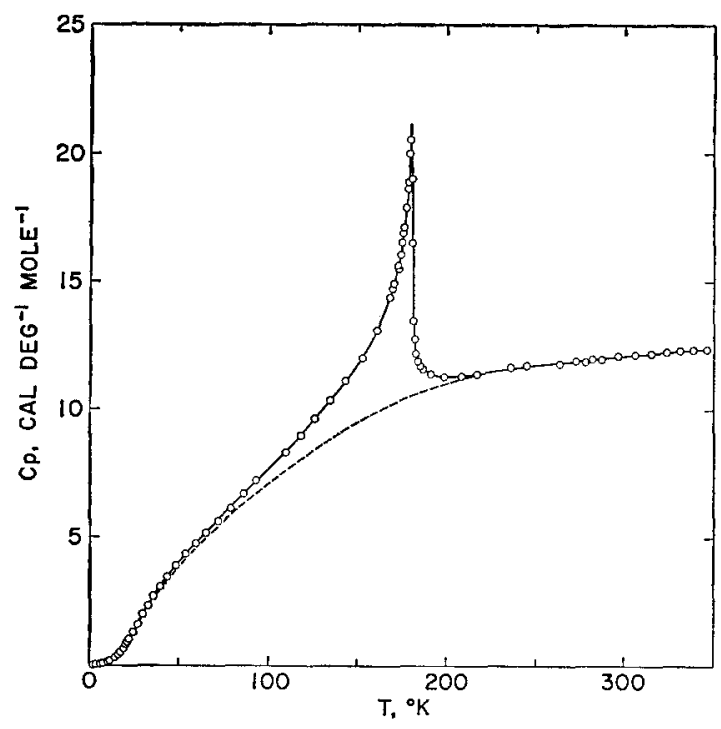

FIG. 1. The heat capacity of uranium monosulfide showing the magnetic transition. Circles represent the experimental values and the dashed curve represents the estimated lattice plus electronic contributions.

\section{RESULTS AND DISCUSSION}

\section{A. Heat Capacity}

The data are based upon a defined thermochemical calorie equal to $4.1840 \mathrm{~J}$, an ice point of $273.15^{\circ} \mathrm{K}$, and a molecular weight of 270.09 for uranium monosulfide.

Experimental values for the heat capacity from the higher temperature set of data are presented in Table I. Temperature increments employed in the measurements may usually be deduced from the differences in the adjacent mean temperatures. Values of $\Delta T$ have been indicated for certain runs for which the tabulated $C_{p}$ does not represent the limiting value of $\Delta H / \Delta T$ as a consequence of the magnitude of $\Delta T$. Except for these runs, the data have been adjusted for "curvature" occasioned by the finite temperature increments used for the measurements. The measurements are considered to have a probable error decreasing from about $5 \%$ at $8^{\circ} \mathrm{K}$ to $2 \%$ at $12^{\circ} \mathrm{K}$ and to about $0.2 \%$ above $25^{\circ} \mathrm{K}$ except in the region of the anomaly. These data are also presented in Fig. 1, in which the shape of the anomaly with a maximum at $180.1^{\circ} \mathrm{K}$ can be seen.

The data from the lower temperature set are given in order of ascending temperature in Table II. The apparent $C_{p}$ values were calculated as if the sample were pure US, and the corrected $C_{p}$ values were obtained from the apparent ones by applying a correction for the presence of 0.0117 mole $\% \mathrm{UO}_{2}$ and 0.0036 mole \% UOS. The heat capacity of $\mathrm{UO}_{2}$ was taken from Westrum and Huntzicker, ${ }^{14}$ and the heat capacity of UOS was taken as the average of the heat capacities of

${ }^{14}$ E. F. Westrum, Jr., and J. J. Huntzicker (unpublished data).
$\mathrm{UO}_{2}{ }^{14}$ and $\mathrm{US}_{2}{ }^{15}$ since the heat capacity of UOS has not been reported. It is estimated that the corrected $C_{p}$ values given in Table II have a probable error of $0.5 \%$ or less. These data are represented by circles in Fig. 2 as $C / T$ vs $T^{2}$.

Heat-capacity values presented at selected temperatures in Table III were taken from smooth curves provided by polynomial functions fitted by leastsquares to the experimental points from both sets of data, except that a large scale plot of $C_{p}$ vs $T$ was used from $170^{\circ}$ to $190^{\circ} \mathrm{K}$. This plot was drawn to accord with the runs having small temperature increments as well as with the enthalpy increments through the entire region. In the region of overlap, the two sets of data agree well within the estimated probable errors.

\section{B. Resolution of Electronic, Magnetic, and Lattice Contributions near $0^{\circ} \mathrm{K}$}

The nature of the compound suggests that at the lowest temperatures the heat capacity can be represented by an equation of the form

$$
C_{p}=\gamma T+b T^{3 / 2}+c T^{3},
$$

in which the term linear in $T$ represents the conduction electrons, the $T^{3 / 2}$ term is the magnetic contribution, and the $T^{3}$ term is the lattice contribution reduced to the Debye limiting law.

The magnetic coefficient $b$ was evaluated as $2.627 \times 10^{-4} \mathrm{cal}^{\circ} \mathrm{K}^{-5 / 2} \mathrm{~mole}^{-1}$ from the formula given by Dyson ${ }^{16}$ for an ideal Heisenberg ferromagnet of $\operatorname{spin}=\frac{1}{2}$ in a rocksalt-type crystalline lattice with $T_{c}=180.1^{\circ} \mathrm{K}$.

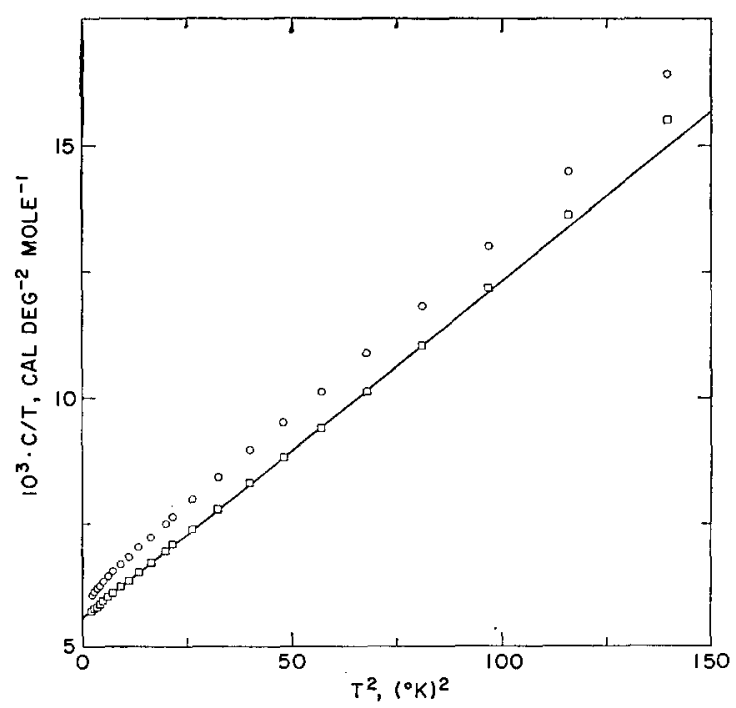

FIg. 2. $C / T$ vs $T^{2}$ for uranium monosulfide. The circles represent the experimental heat capacity determinations corrected to the composition US. The squares show the corresponding values after adjustment for the magnetic contribution by $\mathrm{Eq}$. (2). The line is the least-squares fit described in the text.

${ }^{15}$ E. F. Westrum, Jr., and F. C. Grønvold (unpublished data). ${ }^{16}$ F. J. Dyson, Phys. Rev. 102, 1230 (1956). 
In Fig. 2 the squares represent the values of

$$
C / T=C_{p} / T-2.627 \times 10^{-4} T^{1 / 2} .
$$

The other two coefficients were then computed from the corrected heat-capacity values between 1.5 and $9^{\circ} \mathrm{K}$ (cf. Table II) by least squares. The electronic coefficient $\gamma$ has a value of $5.588 \times 10^{-3} \mathrm{cal}^{\circ} \mathrm{K}^{-2} \mathrm{~mole}^{-1}$; the lattice coefficient $c$ is $6.752 \times 10^{-5} \mathrm{cal}^{\circ} \mathrm{K}^{-4} \mathrm{~mole}^{-1}$, which corresponds to a Debye $\theta$ of $190^{\circ} \mathrm{K}$ for three degrees of freedom. The line in Fig. 2 represents the computer fit. These values of $\gamma$ and $c$ are more accurate than those given earlier $\left(\gamma=4.4 \times 10^{-3} \mathrm{cal}^{\circ} \mathrm{K}^{-2} \mathrm{~mole}^{-1}\right.$ and $c=8.8 \times 10^{-5} \mathrm{cal}^{\circ} \mathrm{K}^{-4}$ mole $\left.^{-1}\right)$ because the earlier ${ }^{1}$ analysis ignored the $T^{3 / 2}$ term, was based on less accurate data at the lowest temperatures, and used data extending to a relatively high temperature.

\section{The Ferromagnetic Transition}

It is of interest to calculate the magnetic contribution to the entropy and enthalpy from the experimental data. For this purpose an estimate of the sum of the electronic and lattice contributions to the heat capacity of uranium monosulfide, $C_{E}+C_{L}$, is needed. An estimate might be provided by the heat capacity of the isostructural, diamagnetic compound thorium monosulfide, but since these data were not available, the following procedure was used. The magnetic heat capacity $C_{M}$ was calculated from $0^{\circ}$ to $80^{\circ} \mathrm{K}$ by the equation

$$
\begin{aligned}
C_{M}=2.627 \times 10^{-4} T^{3 / 2}+1.350 \times 10^{-6} T^{5 / 2} & \\
& +9.949 \times 10^{-9} T^{7 / 2} .
\end{aligned}
$$

Equation (3), obtained from Dyson's ${ }^{16}$ Eqs. (70) and (135) with $T_{c}$ equated to $180.1^{\circ} \mathrm{K}$, is expected to be valid for $T<T_{c} / 2 .{ }^{16} \mathrm{~A}$ curve of $\left(C_{p}-C_{M}\right)$ vs $T$ was drawn up to $80^{\circ} \mathrm{K}$ and then extended to join the experimental $C_{p}$ curve at $230^{\circ} \mathrm{K}$. This curve, used as an approximation for $C_{E}+C_{L}$, is represented between $35^{\circ}$ and $230^{\circ} \mathrm{K}$ by the dashed line in Fig. 1. Below $35^{\circ} \mathrm{K}$ the dashed line lies too close to the $C_{p}$ curve to be distinguished in the figure.

The magnetic entropy corresponding to the difference between the two curves of Fig. 1 is $1.49 \mathrm{cal}^{\circ} \mathrm{K}^{-1} \mathrm{~mole}^{-1}$ from $0^{\circ}$ to $180.1^{\circ} \mathrm{K}$ and $0.13 \mathrm{cal}^{\circ} \mathrm{K}^{-1} \mathrm{~mole}^{-1}$ from $180.1^{\circ}$ to $230^{\circ} \mathrm{K}$, a total of $1.6_{2} \mathrm{cal}^{\circ} \mathrm{K}^{-1} \mathrm{~mole}^{-1}$. The value of $1.6_{2}$ for the total magnetic entropy is uncertain by about \pm 0.2 but is to be preferred to the earlier estimate ${ }^{1}$ of $1.17 \mathrm{cal}^{\circ} \mathrm{K}^{-1}$ mole $^{-1}$ in which no account was taken of the magnetic contribution below $80^{\circ} \mathrm{K}$. Similarly, the magnetic enthalpy is $206 \mathrm{cal} \mathrm{mole}^{-1}$ from $0^{\circ}$ to $180.1^{\circ} \mathrm{K}$ and $25 \mathrm{cal} \mathrm{mole}^{-1}$ from $180.1^{\circ}$ to $230^{\circ} \mathrm{K}$, or a total of $231 \pm 20 \mathrm{cal} \mathrm{mole}^{-1}$.

It is also of interest to compare the present results with those obtained from magnetic studies, which may be summarized briefly as follows. After the observation that uranium monosulfide is ferromagnetic below

\begin{tabular}{|c|c|c|c|c|}
\hline$T$ & $C_{p}^{\circ}$ & $S^{\circ}$ & $H^{\circ}-H_{0}^{\circ}$ & $-\left(G^{\circ}-H_{0}^{\circ}\right) / T$ \\
\hline 5 & 0.0393 & 0.0327 & 0.0863 & 0.0155 \\
\hline 10 & 0.1324 & 0.0839 & 0.4812 & 0.0358 \\
\hline 15 & 0.3629 & 0.1748 & 1.6406 & 0.0654 \\
\hline 20 & 0.7967 & 0.3339 & 4.4571 & 0.1110 \\
\hline 25 & 1.381 & 0.5727 & 9.8616 & 0.1782 \\
\hline 30 & 2.002 & 0.8795 & 18.323 & 0.2687 \\
\hline 35 & 2.587 & 1.2327 & 29.819 & 0.3808 \\
\hline 40 & 3.112 & 1.6130 & 44.087 & 0.5108 \\
\hline 45 & 3.587 & 2.0074 & 60.853 & 0.6551 \\
\hline 50 & 4.019 & 2.4080 & 79.884 & 0.8103 \\
\hline 60 & 4.791 & 3.2106 & 124.02 & 1.1436 \\
\hline 70 & 5.493 & 4.0023 & 175.47 & 1.4956 \\
\hline 80 & 6.183 & 4.7808 & 233.84 & 1.8577 \\
\hline 90 & 6.894 & 5.5498 & 299.21 & 2.2253 \\
\hline 100 & 7.611 & 6.3135 & 371.76 & 2.5960 \\
\hline 110 & 8.334 & 7.0726 & 451.46 & 2.9684 \\
\hline 120 & 9.101 & 7.8303 & 538.59 & 3.3420 \\
\hline 130 & 9.922 & 8.5909 & 633.67 & 3.7165 \\
\hline 140 & 10.79 & 9.3577 & 737.19 & 4.0920 \\
\hline 150 & 11.74 & 10.134 & 849.73 & 4.469 \\
\hline 160 & 12.93 & 10.927 & 972.72 & 4.848 \\
\hline 170 & 14.79 & 11.761 & 1110.4 & 5.229 \\
\hline 180 & 20.91 & 12.722 & 1278.8 & 5.618 \\
\hline 190 & 11.43 & 13.407 & 1405.3 & 6.011 \\
\hline 200 & 11.27 & 13.988 & 1518.6 & 6.395 \\
\hline 210 & 11.31 & 14.538 & 1631.3 & 6.770 \\
\hline 220 & 11.43 & 15.067 & 1745.0 & 7.135 \\
\hline 230 & 11.53 & 15.577 & 1859.8 & 7.491 \\
\hline 240 & 11.62 & 16.070 & 1975.5 & 7.838 \\
\hline 250 & 11.71 & 16.546 & 2092.2 & 8.177 \\
\hline 260 & 11.80 & 17.007 & 2209.7 & 8.508 \\
\hline 270 & 11.88 & 17.454 & 2328.0 & 8.831 \\
\hline 280 & 11.95 & 17.887 & 2447.2 & 9.147 \\
\hline 290 & 12.03 & 18.308 & 2567.1 & 9.456 \\
\hline 300 & 12.10 & 18.717 & 2687.8 & 9.757 \\
\hline 310 & 12.16 & 19.114 & 2809.0 & 10.053 \\
\hline 320 & 12.23 & 19.502 & 2931.0 & 10.342 \\
\hline 330 & 12.29 & 19.879 & 3053.6 & 10.625 \\
\hline 340 & 12.34 & 20.246 & 3176.7 & 10.903 \\
\hline 350 & 12.40 & 20.605 & 3300.4 & 11.175 \\
\hline 273.15 & 11.90 & 17.59 & 2366 & 8.93 \\
\hline \multirow[t]{2}{*}{298.15} & 12.08 & 18.64 & 2665 & 9.70 \\
\hline & \pm 0.02 & \pm 0.05 & \pm 7 & \pm 0.02 \\
\hline
\end{tabular}

TabLE III. Thermodynamic functions of uranium monosulfide. Units: cal, ${ }^{\circ} \mathrm{K}$, mole.

$180^{\circ} \mathrm{K},{ }^{2}$ Kazmierowicz ${ }^{17}$ found that the saturation magnetic moment at $0^{\circ} \mathrm{K}$ (based on an extrapolation from $4.2^{\circ} \mathrm{K}$ ) is $1.05 \pm 0.03$ Bohr magnetons. This value is more reliable than a preliminary value of $1.02-\mathrm{Bohr}$ magnetons reported from the same laboratory ${ }^{18}$ which was based on an extrapolation from $77^{\circ} \mathrm{K}$. It is also more reliable than the value $1.61-\mathrm{Bohr}$ magnetons

${ }^{17}$ C. W. Kazmierowicz, Argonne National Laboratory Report ANL-6731 (1963).

${ }_{18}$ M. A. Kanter and C. W. Kazmierowicz, J. Appl. Phys. 35, 1053 (1964). 
reported by Suski and Trzebiatowski, ${ }^{19}$ who stated that their value was only approximate because it involved an extrapolation from $80^{\circ}$ to $0^{\circ} \mathrm{K}$. These authors ${ }^{19,20}$ found that the paramagnetic moment is $2.22-\mathrm{Bohr}$ magnetons, the Curie-Weiss constant is $185^{\circ} \mathrm{K}$, and the Curie temperature is $180^{\circ} \mathrm{K}$. Didchenko and Gortsema ${ }^{21}$ reported a paramagnetic moment of 2.46Bohr magnetons and a Curie temperature of $180^{\circ} \mathrm{K}$. Allbutt, Junkison, and Dell ${ }^{22}$ found that the paramagnetic moment is $2.25 \pm 0.05-\mathrm{Bohr}$ magnetons, the Curie-Weiss constant $173^{\circ} \mathrm{K}$, and the Curie temperature $178^{\circ} \pm 2^{\circ} \mathrm{K}$.

These measurements of the Curie temperature are in agreement with the temperature at which the heatcapacity curve has a maximum, $180.1 \pm 0.5^{\circ} \mathrm{K}$. Of course, these temperatures are not expected to agree exactly because the magnetic measurements give the temperature at which the spontaneous magnetization $\sigma$ becomes zero, whereas the heat-capacity maximum occurs where $\left(d \sigma^{2} / d T\right)=0$ according to the Weiss model of ferromagnetism.

If the magnetism arises entirely from electron spins, the magnitude of the saturation magnetic moment at $0^{\circ} \mathrm{K}$ indicates one electron spin per US molecule. On the assumption that these spins can be considered localized, the change in magnetic entropy between the ground state at $0^{\circ} \mathrm{K}$ with completely ordered spins to a hightemperature state with completely disordered spins is then calculated to be $R \ln 2$ or 1.38 cal ${ }^{\circ} \mathrm{K}^{-1} \mathrm{~mole}^{-1}$. This value is somewhat lower than the experimental value, $1.6_{2} \pm 0.2 \mathrm{cal}^{\circ} \mathrm{K}^{-1} \mathrm{~mole}^{-1}$, but the disagreement is only slightly larger than the estimated experimental error. This may be fortuitous, however, for the spins probably cannot be considered localized in an electrical conductor. Also, for one localized spin per molecule with $g=2$, the paramagnetic moment should be $1.73-\mathrm{Bohr}$ magnetons, significantly lower than the observed values of 2.22 - to $2.46-\mathrm{Bohr}$ magnetons. ${ }^{19-22} \mathrm{~A}$ more sophisticated calculation involving band theory would be desirable, but so far none has been reported.

\section{Thermodynamic Functions}

The thermodynamic functions entropy $\left[S^{\circ}\right]$, enthalpy increment $\left[H^{\circ}-H_{0}^{\circ}\right]$, and Gibbs energy function $\left[-\left(G^{\circ}-H_{0}^{\circ}\right) / T\right]$-are given at selected temperatures in Table III. These were obtained by appro-

${ }^{19} \mathrm{~W}$. Suski and W. Trzebiatowski, Bull. Acad. Polon. Sci. Ser. Sci. Chim. 12, 277 (1964).

${ }^{20} \mathrm{~W}$. Trzebiatowski and W. Suski, Roczniki Chem. 37, 117 (1963)

${ }^{21}$ R. Didchenko and F. P. Gortsema, Inorg. Chem. 2, 1079 (1963).

${ }^{22}$ M. Allbutt, A. R. Junkison, and R. M. Dell, "Magnetic Properties of Some Refractory Compounds," in Compounds of Interest in Nuclear Reactor Technology, J. T. Waber, P. Chiotti, and W. N. Miner, Eds. (Am. Inst. Mining, Met. Petrol. Engrs., New York, 1964), pp. 65-81. priate integrations of the polynomials representing the heat capacity data with a high-speed digital computer. The extrapolation to $0^{\circ} \mathrm{K}$, where the entropy is assumed to be zero, was made by Eq. (1); the transition region was integrated by numerical quadrature. The precision of these functions is considered to correspond to a probable error of $0.25 \%$ above $100^{\circ} \mathrm{K}$. An additional digit beyond those significant is given in this table for internal consistency and to permit interpolation and differentiation. Entropy and Gibbs-energy values have not been adjusted for nuclear spin and isotopic mixing contributions and are hence practical values for use in chemical thermodynamic calculations.

\section{E. Thermodynamics of Formation of Uranium Monosulfide}

Combining the entropy of uranium monosulfide given in Table III with the entropies of $\alpha$-uranium $\left(12.00 \pm 0.02 \mathrm{cal}^{\circ} \mathrm{K}^{-1} \mathrm{~mole}^{-1}\right)^{23}$ and of rhombic sulfur $\left(7.62 \pm 0.04 \mathrm{cal}^{\circ} \mathrm{K}^{-1} \mathrm{~mole}^{-1}\right)^{24}$ at $298.15^{\circ} \mathrm{K}$, we obtain the entropy of formation of uranium monosulfide, $\Delta S f^{\circ}{ }_{298.15}=-0.98 \pm 0.07 \mathrm{cal}^{\circ} \mathrm{K}^{-1} \mathrm{~mole}^{-1}$. This value may be combined with values of $\Delta H f^{\circ}{ }_{298.16}$ obtained by other workers to yield $\Delta G f^{\circ}{ }_{298.15}$.

Cater, Gilles, and Thorn ${ }^{25}$ have found $\Delta H^{\circ}{ }_{2300}=$ $271.2 \pm 2.0 \mathrm{kcal} \mathrm{mole}{ }^{-1}$ and $\Delta S^{\circ}{ }_{2300}=65.49 \pm 0.88 \mathrm{cal}$ ${ }^{\circ} \mathrm{K}^{-1}$ mole ${ }^{-1}$ for the sublimation of uranium monosulfide to uranium and sulfur atoms at $2300^{\circ} \mathrm{K}$. These results were derived from measurements on the vaporization of uranium monosulfide and from mass-spectrometric measurements by Cater, Rauh, and Thorn..$^{26}$ Using these numbers with Rauh and Thorn's value ${ }^{27}$ for the enthalpy of sublimation of $\alpha$-uranium metal at $298.15^{\circ} \mathrm{K}$, with estimated thermodynamic properties of uranium monosulfide between room temperature and $2300^{\circ} \mathrm{K}$, and with literature values of the thermodynamic properties of gaseous uranium and sulfur atoms (including the enthalpy of formation of gaseous sulfur atoms), they calculated the enthalpy of formation of uranium monosulfide at $298.15^{\circ} \mathrm{K}$ to be $\Delta H f^{\circ}{ }_{298.15}=$ $-90 \pm 5 \mathrm{kcal} \mathrm{mole}^{-1}$. From this and $\Delta S f^{\circ}{ }_{298.15}$ we obtain $\Delta G f_{298.15}^{\circ}=-90 \pm 5 \mathrm{kcal} \mathrm{mole}{ }^{-1}$.

Recently the enthalpy of formation at $298.15^{\circ} \mathrm{K}$ has been obtained more directly by burning uranium monosulfide in fluorine. O'Hare, Settle, Feder, and Hubbard ${ }^{28}$ reported an enthalpy of combustion of $-2708.8 \pm 3.9$

${ }^{23}$ H. E. Flotow and D. W. Osborne, Phys. Rev. 151, 564 (1966).

${ }^{24}$ K. K. Kelley and E. G. King, U.S. Bur. Mines Bull. 592 (1961)

${ }^{25}$ E. D. Cater, P. W. Gilles, and R. J. Thorn, J. Chem. Phys. 35,608 (1961).

${ }_{26}$ E. D. Cater, E. G. Rauh, and R. J. Thorn, J. Chem. Phys. 35, 619 (196i).

${ }^{27}$ E. G. Rauh and R. J. Thorn, J. Chem. Phys. 22, 1414 (1954).

${ }_{28}$ P. A. G. O'Hare, J. L. Settle, H. M. Feder, and W. N. Hubbard, "The Thermochemistry of Some Uranium Compounds," in Thermodynamics of Nuclear Materials with Emphasis on Solution Systems (International Atomic Energy Agency, Vienna, 1967). 
cal $g^{-1}$ for the reaction

$$
\mathrm{US}_{1.011}(\mathrm{c})+6.033 \mathrm{~F}_{2}(\mathrm{~g})=\mathrm{UF}_{6}(\mathrm{~g})+1.011 \mathrm{SF}_{6}(\mathrm{~g}),
$$

and from this they obtained $\Delta H f^{\circ}{ }_{298.15}=-73.2 \pm 3.5$ $\mathrm{kcal} \mathrm{mole} \mathrm{e}^{-1}$ for the formation of $\mathrm{US}_{1.011}$. In view of the indicated uncertainty this value will also be considered appropriate for the stoichiometric composition, $\mathrm{US}_{1.000}$. The corresponding value for the Gibbs energy of formation is $\Delta G f_{298.15}^{\circ}=-72.9 \pm 3.5 \mathrm{kcal} \mathrm{mole}^{-1}$.

The reason for the large discrepancy between the enthalpy of formation obtained from high-temperature measurements and that obtained from combustion in fluorine is not known. The present authors believe that the second of these is to be preferred.

\section{ACKNOWLEDGMENTS}

The authors appreciate the contributions of others from both laboratories. At the Argonne National Laboratory, we are indebted to R. J. Thorn for his interest and helpful discussion, to J. Tague for assistance with the thermal measurements, to D. Huff for spectrographic analyses, to B. Holt, A. Venters, and D. Pettis for oxygen determinations, to A. Essling and R. Bane for uranium determinations, to $P$. Peterson for sulfur determinations, and to J. Whitaker and S. Siegel for $\mathrm{x}$-ray structural analyses. R. R. Radebaugh performed many of the heat-capacity determinations at the University of Michigan. The financial sponsorship of the U. S. Atomic Energy Commission is acknowledged with gratitude.

\title{
Analysis of the Paramagnetic Resonance and Optical Spectra of $d^{3,7}$ Ions in Tetragonal Crystal Fields. I. Orbitally Nondegenerate Ground States
}

\author{
J. P. Jesson \\ Central Research Department, ${ }^{*}$ E. I. du Pont de Nemours and Company, Experimental Station, Wilmington, Delaware
}

(Received 29 May 1967)

\begin{abstract}
The ligand-field Hamiltonian, including spin-orbit coupling and all states of the configuration, has been diagonalized for the $d^{3,7}$ ions in tetragonal environments. The $g$-tensor components have been determined within the lowest two Kramers doublets in cases where the ground state is orbitally nondegenerate. The variation of $D, g_{l}$, and $g_{+}$with the parameters of the tetragonal potential has been investigated for parameter values appropriate to the $\mathrm{Co}^{2+}$ ion in $D_{2 d}$ symmetry. The results are compared with those obtained from simple perturbation expressions which have been used in the literature. Parameters for the extended spin Hamiltonian are evaluated directly. Matrices for the tetragonal potential are used to discuss optical and paramagnetic resonance data for $\mathrm{Cs}_{3} \mathrm{CoCl}_{6}$ and $\mathrm{Co}^{2+}$ in $\mathrm{CaF}_{2}$. Polarized single-crystal optical data for $\mathrm{Cs}_{3} \mathrm{CoCl}_{5}$ at $4.2^{\circ} \mathrm{K}$ are described for the ${ }^{4} T_{1}\left({ }^{4} F\right)$ and ${ }^{4} T_{1}\left({ }^{4} P\right)$ states.
\end{abstract}

\section{INTRODUCTION}

There has been an increased interest in recent years in the effect of low-symmetry components of the crystal field on the optical spectra of transition-metal systems ${ }^{1}$ and on the resonance properties of the ground states., ${ }^{2,3}$ Emphasis has been placed on the complete inclusion of all states of the configuration and of the spin-orbit coupling.

In the present paper a complete crystal-field calculation of the effects of tetragonal distortions on the optical and paramagnetic resonance properties of $d^{3,7}$ ions is presented. The problem including spin-orbit effects and all states of the configuration reduces to two $30 \times 30$ matrices corresponding to the $60 \mathrm{Kramers}$ doublets of the $d^{3,7}$ configuration. The paramagnetic resonance properties are then evaluated within the

\footnotetext{
* Contribution No. 1342.

I R. M. Macfarlane, J. Chem. Phys. 39, 3118 (1963).

2 R. M. Macfarlane, J. Chem. Phys. 40, 373 (1964).

${ }^{3}$ H. M. Gladney and J. D. Swalen, J. Chem. Phys. 42, 1999 (1965).
}

lowest or lowest two doublets depending on the orbital degeneracy of the ground state.

We consider principally the problem of $\mathrm{Co}^{2+}$ in an environment of $D_{2 d}$ symmetry, taking as an example the $\mathrm{Cs}_{3} \mathrm{CoCl}_{5}$ system. With appropriate variation of the magnitude and sign of the input parameters, square planar, and tetragonally distorted octahedral $d^{3,7}$ ions can also be treated.

The parameters $D s$ and $D t$ for the $Y_{2}{ }^{0}$ and $Y_{4}{ }^{0}$ contributions to the low-symmetry component of the field ${ }^{4}$ are most convenient for the treatment of the orbitally nondegenerate problem. The zero-field splitting, $g$ anisotropy, and splitting of the ${ }^{4} T_{2}$ excited state are largely determined by $D t$ except in cases where $D s \gg D t$.

Brief consideration is given to the optical and paramagnetic resonance data for the pure $O_{h}$ system $\mathrm{Co}^{2+}$ in $\mathrm{CaF}_{2}$. The calculated parameters of the extended

\footnotetext{
${ }^{4}$ W. Moffitt and C. J. Ballhausen, Ann. Rev. Phys. Chem.7, 107 (1956).
} 